\title{
Studies on the Circulatory System of Adult Beetles Blaps sulcata Laporte and Blaps polychresta Forskal (Coleoptera, Tenebrionidae)
}

\author{
Abdel- Moneim H. El-Zoheiry and Salah El Din I. Osman \\ Zoology Department, Faculty of Science, Alexandria University, Egypt.
}

\begin{abstract}
The aim of the present study is to describe the anatomy and histology of heart, alary muscles, pericardial cells, fat body and hemocytes of aduit beetles, Blaps sulcata and Blaps polychresta. The dorsal vessel in both beetles Blaps sulcata Laporte and Blaps polychresta Forskal is made up of an elongated aorta extending along the thorax and head regions. The six chambers of the heart together with the six pairs of alary muscles are present in the abdominal region. Darkly pigmented, oval or rounded - shaped and mono or binucleated pericardial cells are present in the pericardial sinus, on each side of the heart. The haemolymph is colourless and undergoes coagulation in both beetles. Four types of the haemocytes in Blaps sulcata have been distinguished namely, prohaemocyts, plasmatocytes, granulocytes and oenocytoids. In smears of blood of Blaps polychresta, and in sections of fat body of this beetle, adipose cells were observed fixed to fat body lobes in addition to the four types previously mentioned in Blaps sulcata.
\end{abstract}

Keywords: Blaps spp., heart, pericardial cells, haemocytes, fat body, alary muscles.

\section{INTRODUCTION}

Blaps sulcata Laporte is a black desert beetle distributed in semi-arid habitats such as Salloum, Marsa Matruh and Siwa. The Taxonomical status of Blaps spp. had been reviewed by Alfieri (1976). He recorded 15 species of the genus Blaps in Egypt. Blaps spp. belongs to tribe Blaptini, subfamily Blaptinae, family Tenebrionidae, superfamily Cucujoidea, section Heteromera, suborder Polyphaga, order Coleoptera. Blaps sulcata and Blaps polychresta are nocturnal scavenger ground beetles. Blaps polychresta is found in humid locations such as back- buildings and gardens. Hegazi et al (1978) reported Blaps sulcata among the insects associated with Lygos plants in ElOmyed (85 km, west of Alexandria) and in the rocky plateau of Gabal El- Khashm. It was also found in great numbers in the rocky plateau of a reclaimed desert region, west of Burg El-Arab, Alexandria, It represents about half the population of ground beetles in this area and it is rarely found in sandy locations and it feeds on Thymelaea hirsuta L. shrubs which are common in this region. In both beetles, Blaps spp., the male is smaller than the female, walking clumsily and has a hairy pheromone gland between the first and second abdominal sternites (Fig.2). Sorour (1993) had studied the fine structure of pheromone gland in adult male Blaps polychresta. Blaps spp., as well as many tenebrionid beetles are characterized by the so called defensive pygidial glands which secrete benzoquinone derivatives which are found to be carcinogenic and may be considered as antitumor agents, and some of these secretions have an antimicrobial activity and may conceivably provide protection against both predators and microorganisms (Roth \& Eisner, 1962). Blaps spp. were found to be predators which could destroy some dipterous larvae of $L$. sericata flies under experimental. conditions (Tanagho, 1989; TagiZade \& Gadzhizalov, 1989)

Very small microchelid mites were observed to live in a phoretic association with Blaps sulcata. The mites were observed to be located at the thoracic sternites and at the pleural coxal processes of the pleurites. This phenomenon has been particularly observed among the insects reared under laboratory conditions more frequently than among the field collected specimens (El- Karadisy, personal communication). Blaps sulcata was reported to feed on isopodes which aid soil aeration (Sharkawy, personal communication), hence it may be considered as a natural enemy for these beneficial isopodes.

Adamski et al (2019) reported that beetles are considered as model organisms in physiological, biomedical and environmental studies and they added that coleopterans are a source of compounds with potential antimicrobial and antitumor activity which could likely be used in cancer therapy and immunology.

The heart and its structure had been scarcely investigated in Coleoptera. The hemocytes of Tenebrio molitor had been studied by Jones (1964). The blood coagulation had been studied in Blaps spp. and other insects by Grégoire (1953). McCann (1970) studied the position and origin of the alary muscles in relationship to the dorsal diaphragm and the heart wall. The pericardial cells were reported to perform ingestion and encapsulation of tubercle bacelli and others considered them as analogues to the reticule-endothelial tissue and indicated their microphagocytic activity and they were regarded as cardio-regulators. 
Little work had been done on the anatomy and histology of most of the tenebrionid genera. Shalaby et al (1982), Osman et al (1982) studied the anatomy and histology of digestive, reproductive systems of Blaps sulcata. El- Zoheiry (1993), ElZoheiry \& Sorour (1993), El-Zoheiry (1999 a,b) studied the morphology and ultrastructure of pygidial defensive glands, and histology of the accessory reproductive glands in Blaps ploychresta.

The aim of the present study is to describe the anatomy and histology of heart and hemocytes of adult beetles, Blaps sulcata and Blaps ploychresta.

\section{MATERIALS AND METHODS}

Adults Blaps sulcata were collected from Burg El- Arab desert region, 50 Kilometers west of Alexandria. In the laboratory, they were kept in large jars containing sand and stones taken from the original habitat and fed on bread crumbs and plant roots. Adults Blaps polychresta were collected from gardens and reared in the laboratory under normal conditions. The insects were dissected alive in physiological saline solution $(6.5 \% \mathrm{NaCl})$. The closely packed elytra were removed, so the abdominal tergites which appear fairly deep were shown with a capacious isolating space known as subelytral cavity. The heart specimens were fixed for 12 hours in alcoholic Bouin at $37^{\circ} \mathrm{C}$, then dehydrated and cleared in xylol before being embedded in paraffin wax $\left(56^{\circ} \mathrm{C}\right)$. Sections were cut at a thickness of 5-7 um and they had been stained with Ehrlich's haematoxylin, counterstained in alcoholic eosin. The blood smears were fixed in absolute methyl alcohol and stained with diluted Giemsa stain.

\section{RESULTS AND DISCUSSION}

The dorsal vessel occupies the mid dorsal line under the tergum and is surrounded by a pericardial sinus. It is differentiated into the heart and the aorta which proceeds anteriorly to enter the head capsule (Figs. 3,4). In Blaps spp., the heart when examined under the dissecting binocular microscope is seen to be limited by evenly brownish pigmentation. It constitutes six chambers extending in the abdominal region. Romoser (1973) stated that the heart is generally made up of seven to nine chambers in Coleoptera. The first and the sixth chambers are relatively smaller than the rest of the chambers. The sixth chamber ends blindly. The constrictions between the successive heart chambers mark the position of the related ostia. Dorsally, the heart chambers are seen intercrossed by slight invaginations which represent the intersegmental membranes between the tergites. Paired fan-shaped alary muscles (Fig.4) attached to the heart chambers hold the heart in position on the ventral side of the tergum. The aorta (Fig. 4) is a tubular prolongation extending anteriorly through the thorax and enters the head capsule through the occipital foramen. However, Wigglesworth (1939) recorded that the aorta in insects is also contractile but its pulsation could not be observed.

The alary muscles (Fig. 4) are six pairs laterally attached to the corresponding heart chambers. Each pair of alary muscles is connected medially beneath the corresponding heart chamber in a close association with the dorsal diaphragm. They were early reported as elastic elements. In adult Coleoptera, their contractions flatten the dorsal diaphragm. It is reported that the alary muscles are not essential to the rhythmic beat of the heart. McCann (1970) proved their origin from the lateral body wall and they have a cardiac activity function.

The pericardial cells in Blaps sulcata (Fig. 5,6) are present in groups inside the pericardial sinus on the lateral sides in the vicinity of the heart and they are usually guarded by lateral fat lobules. They are rounded or oval in shape having variable sizes and some of them are binucleated and they were concluded to undergo microphagocytosis and active pinocytosis of colloidal albuminoids, which, in turn, become transformed into assimilable substances or being altered into excretory materials.

The fat body (Fig. 9) originates from the coelomic cavities and it is formed from a peripheral layer just below the hypodermis and a visceral layer, which is mainly found in the perivisceral body cavity. The fat cells are closely packed together forming irregular white lobes, each lobe is surrounded by a connective tissue membrane. They measure about 57 um in diameter and possess numerous fat globules of various sizes, their nuclei are densely stained, spherical in shape and measuring about 15 um in diameter, the fat lobes are highly tracheated. In general, the fat reserves play a vital role in metamorphosis, maturation of gametes (El- Zoheiry, 1982).

The hemocytes are considered as a major constituent of the hemolymph. Zlotkin et al. (1973) identified phenoloxidase enzyme in the hemolymph of Blaps sulcata and other tenebrionids. In Blaps scutellata, Byzova (1974) reported the carbonic anhydrase activity. Gullan \& Cranston (2005) and Klowden (2016) reported that the hemocytes have a variety of functions, including phagocytosis of foreign particulate matter, encapsulation of multicellular parasites, coagulation, wound healing after injury, as well as an important role in connective tissue formation and intermediary metabolion. They added that most earlier studies of hemocytes have classified them according to their size, shape, nuclear characteristics and cytoplasmic inclusions and their presumed functions have been inferred from their morphology. Genetic markers have been most recently employed to differentiate the various hemocyte types. 
The hemolymph of Blaps sulcata and Blaps polychresta was observed to undergo coagulation. On the contrary, Grègoire (1953) stated that coagulation is absent in Blaps gigas L., Blaps requieni S1. and Blaps mucronata. Hemocytes are produced during the larval stages from dividing stem cells and from the continued division of hemocytes already found in circulation in adults.

Soliman \& Gad (2020) found that there are four types of hemocytes in stained film of hemolymph of $5^{\text {th }}$ instar larva of silk worm namely, prohemocytes, plasmatocytes, granulocytes and oenocytoids. Four or five types of hemocytes could be observed in the hemolymph of adult Blaps sulcata and Blaps polychresta (Figs. 7,8,9).

1- The prohemocytes: are small round cells that contain a large nucleus and do not engage in phagocytosis. They are believed to be the stem cells that post-embryonically give rise to other types. They measure about $7 \mathrm{um}$ in diameter with deeply stained nuclei (4 um in diameter). Sometimes, they show mitosis and probably represent a stage from which all or most of other types develop (Jones, 1964).

2- The plasmatocytes: are round or ovoid when seen in the freshly obtained hemolymph samples. These shapes are of the normal alive plasmatocytes. They become spindle in shape, fusiform or irregular in prepared mounts. The nuclei were noted to be weakly acidophilic, finely granulated and the cytoplasm granular and basophilic. The cytoplasm stained faintly blue and showed clear vacuoles. The average length of the plasmatocyte is about $20 \mathrm{um}$ and its width is about $15 \mathrm{um}$. The nucleus is about $7 \mathrm{um}$ in length and about 5 um in breadth. Wigglesworth (1972) stated that they had been derived by way of transitional forms from the prohemocytes and they now have an increased amount of cytoplasm; they are exceedingly polymorphic rounded, spindle - shaped or pear-shaped when free in the blood, flattened or drawn into elongated forms when attached to other organs.

3-The granulocytes: They were named as eosinophils and seem to be derivatives of the plasmatocytes (Wigglesworth, 1972). They were thought to be derived from the prohemocytes although some may arise from the plasmatocytes (Romoser, 1973). They are about $12 \mathrm{um}$ in diameter and they were noted to possess clear vacuoles and acidophilic cytoplasm. The nucleus was noted to be small and spherical in shape measuring about $4 \mathrm{um}$. The nucleus had been observed to be laterally situated. Romoser (1973) reported that it is centrally located.

4- The oenocytoids: are so named because they resemble the true oenocytes. They are spherical or ovoid in shape of about 15 um in length and 9 um in width, with darkly stained small homogeneous nuclei of about 5 um in length and $4 \mathrm{um}$ in diameter and with a slightly blue clear basophilic cytoplasm. Although in the fixed preparations, the cytoplasm of oenocytoids appears homogeneous in the fresh state, however, the cytoplasm showed very small spherical inclusions when seen under the phase contrast microscope. Such cells containing inclusions had been referred to as hyaline cells by Jones (1964). They were termed by Lai- Fook (1970) as granulocytophagous hemocytes because the oenocytoids, when examined with electron microscope after staining with uranyl and lead have dense spherical inclusions (Wigglesworth, 1979). They contain the phenoloxidase, released when the cells lyze to initiate the melanization and darkening of hemolymph upon exposure to air and they are also non-motile (Klowden, 2016).

5- The adipohemocytes (adipose cells): are observed fixed to fat body lobes in Blaps polychresta (Fig. 9). They are round cells with cytoplasmic projections and a small nucleus. They may be called as amoebocytes. Klowden (2016) said that their nucleus is surrounded by a large amount of cytoplasm that contains a number of lipid vacuoles. They have been suspected to be wayward fat body cells that have contaminated hemolymph samples in the course of observation, and may not be true hemocytes.
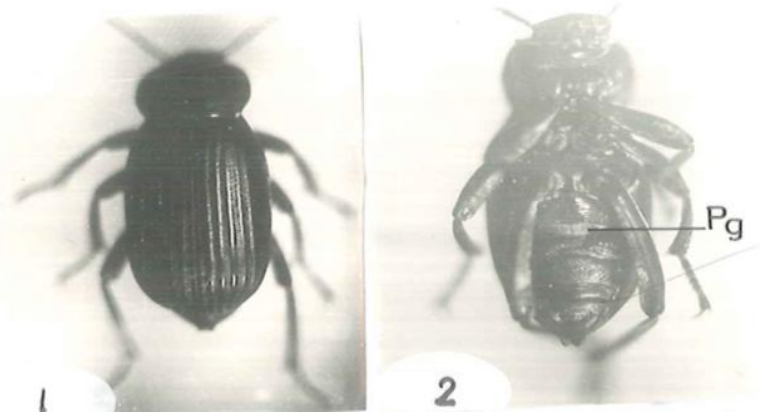

Fig. 1: Showing dorsal view of male Blaps sulcata (X3).

Fig. 2: Showing ventral side of male Blaps sulcata with pheromone gland (Pg) (X3). 


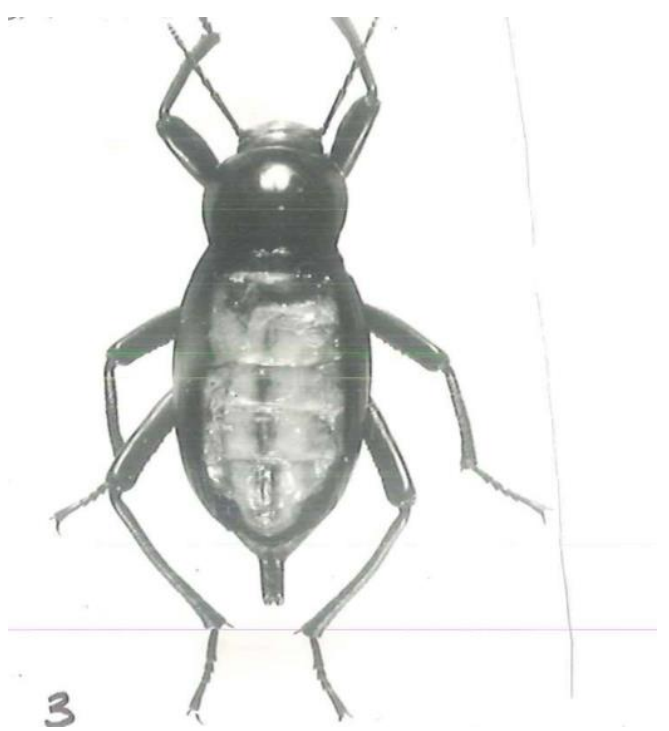

Fig. 3: Showing heart chambers of Blaps polychresta in a dorsal view (normal size).

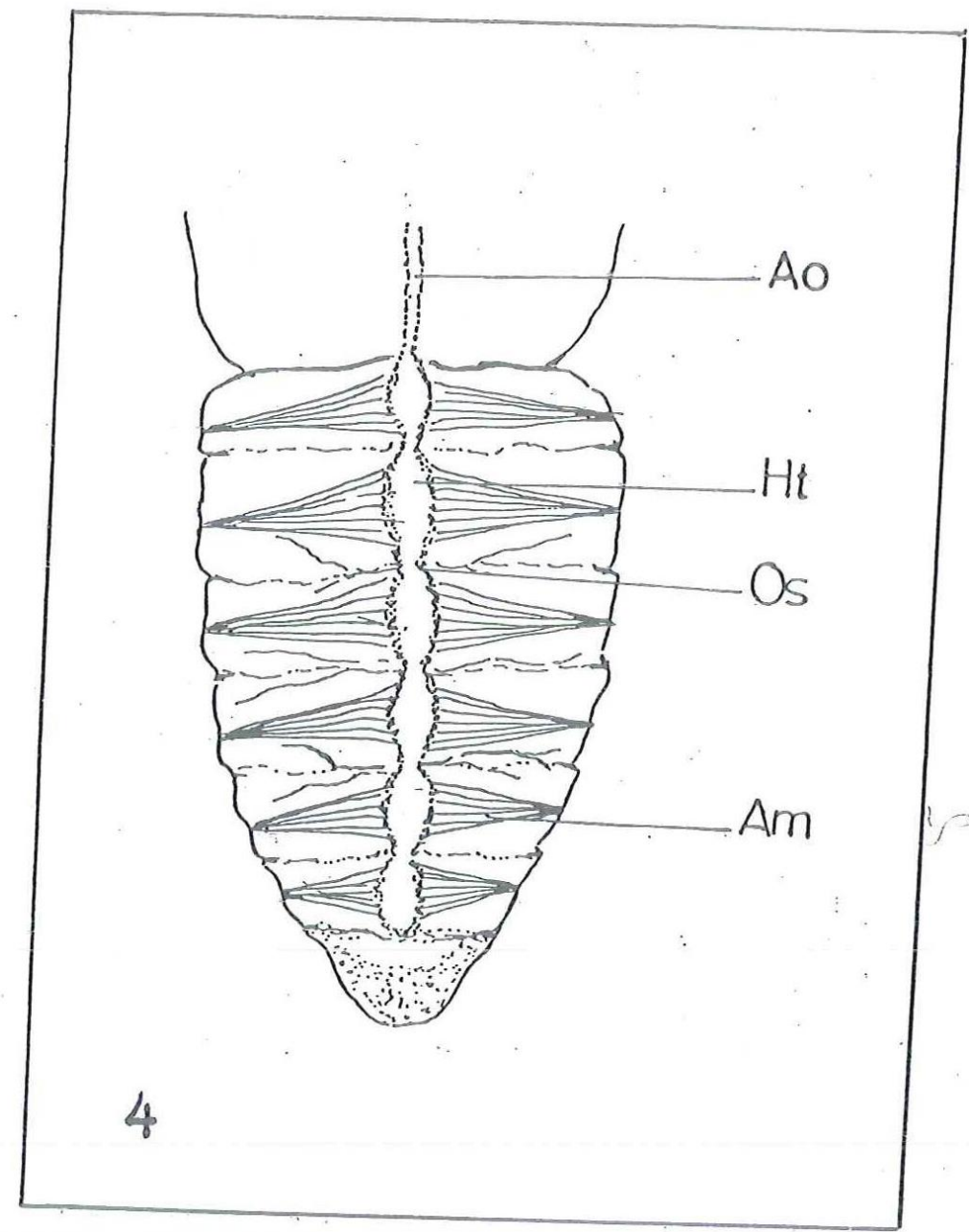

Fig. 4: Showing a diagram of the circulatory system of Blaps sulcata with alary muscle, (Am), aorta (Ao), heart (Ht) and Ostia (Os)(X6). 


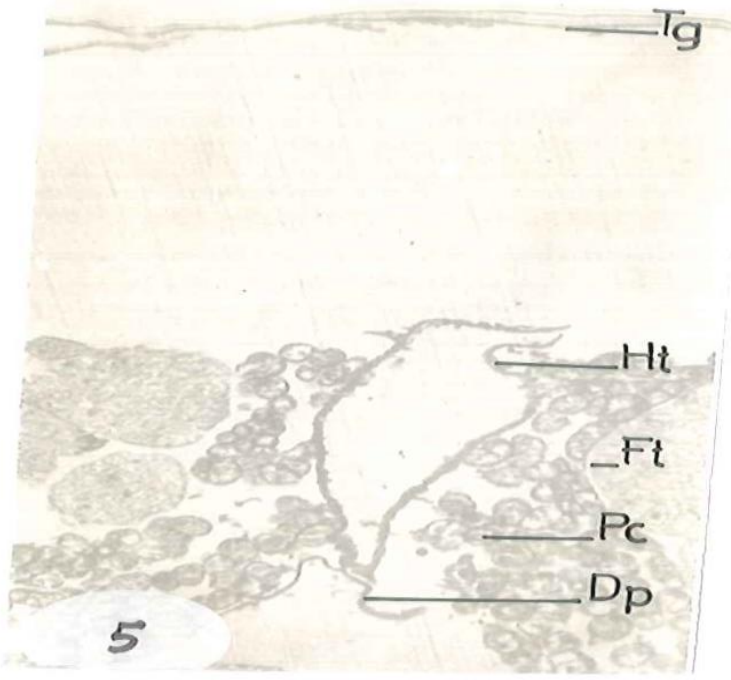

Fig. 5: Showing a transverse section of the heart of Blaps sulcata with dorsal diaphragm (Dp), fat lobule (Ft), heart chamber with heart muscles (Ht), pericardial (Pc) and tergum (Tg)(X60).

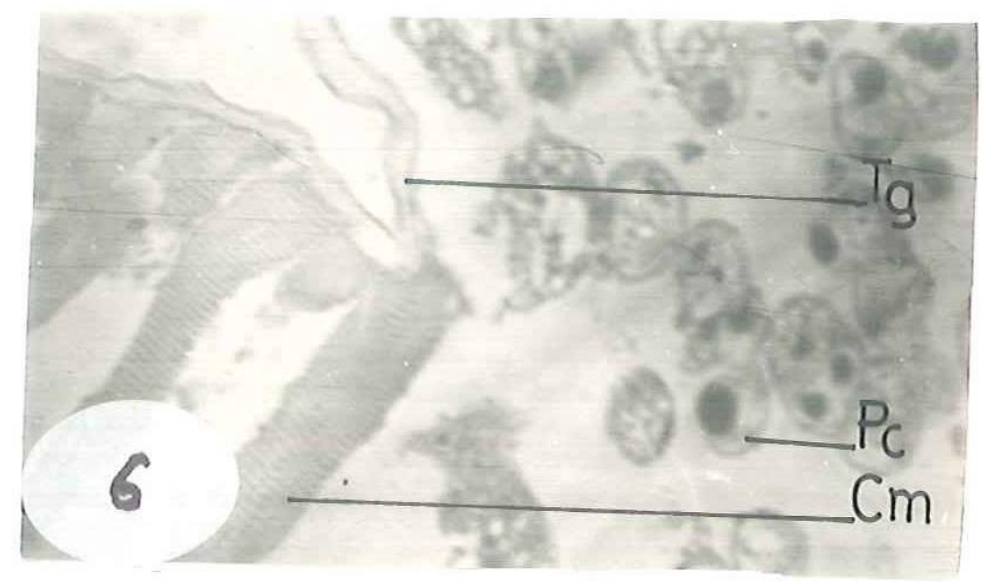

Fig. 6: Showing the pericardial cells of Blaps sulcata with circular muscle fibres (Cm), pericardial cell (Pc) and tergum (Tg).

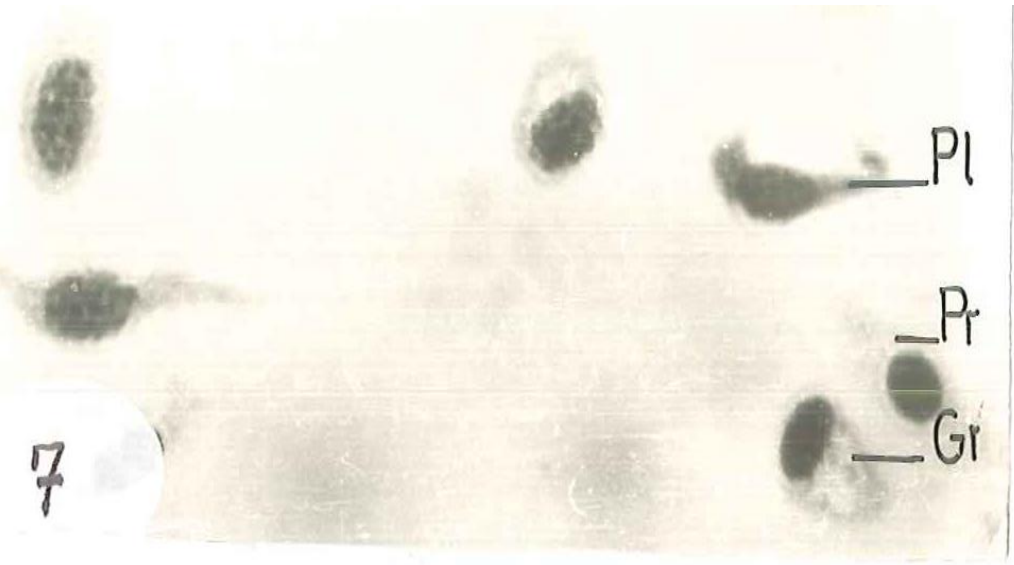

Fig. 7: Showing blood film of Blaps sulcata with granulocyte (Gr), plasmatocyte (PI) and prohemocyte (Pr). (X1000). 


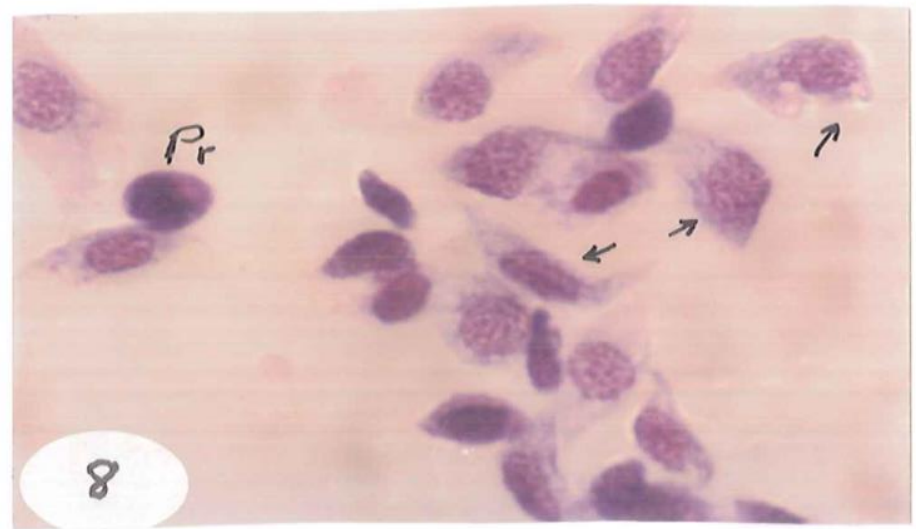

Fig. 8: Showing blood film of Blaps polychresta with different forms of plasmatocytes (arroes) and prohemocyte (Pr). (X1400).

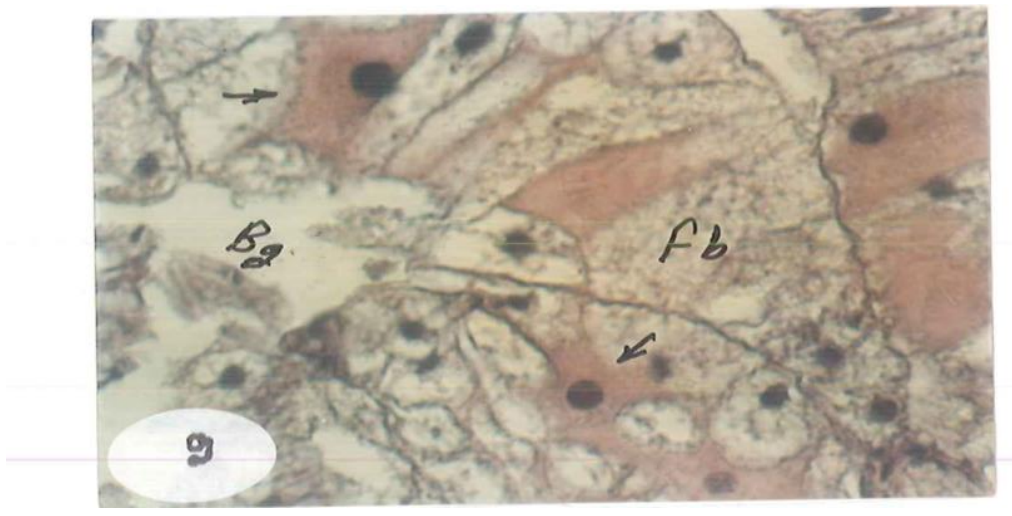

Fig. 9: Showing section of fat body lobes (Fb) with adipose cells (arrows) and blood gaps (Bg) in Blaps polychresta (X1400).

\section{REFERENCES}

Adamski, Z., Bufo, S.A., Chowanski, S. et al (2019): Beetles as model organisms in physiological, biomedical and environmental studies. A review. Frontiers in physiology. volume 10: 1-22.

Alfieri, A. (1976): The Coleoptera of Egypt. A monograph, Memoires de la Societe Entomologique D' Egypte. vol.5, pp.361

Byzova, Yu. B. (1974): Carbonic anhydrase in the hemolymph of the beetles Blaps scutellata. J. Evol. Bioch. Physiol. 9(4): 530-531.

El- Zoheiry, A. H. (1982): Anatomical and histological studies on the adult black desert beetle Blaps sulcata Laporte. M. Sc.Thesis, Fac. Science, Alexandria Univ.pp. 102.

El- Zoheiry, A. H. (1993): Morphological studies on the defensive pygidial glands in the house beetle Blaps polychresta Forskal (Col., Tenebrionidae). J. Egypt. Ger. Soc. Zool. 10 (D): $347-357$.
El- Zoheiry, A. and Sorour, J. (1993): Ultrastructural studies on the defensive pygidial glands of Blaps polychresta (Colcoptera: Tenebrionidae). J. Egypt. Ger. Soc. Zool. 12 (C): 115-133

El- Zoheiry, A. H. (1999a): Histological studies on the bean- shaped accessory glands of the male beetle Blaps polychresta. J. Egypt. Ger Soc. Zoology. 28 (C): 241-258.

El- Zoheiry, A. H. (1999b): Histological studies on the tubular accessory glands in the male beetle Blaps polychresta. J. Egypt. Ger Soc. Zoology. 28 (C): 259-274.

Grégoire, C. (1953): Blood coagulation in arthropods.III. Reactions of insect hemolymph to coagulation inhibitors of vertebrat blood. Biol. Bull. 10: 372-393.

Gullan, P. J and P.S. Cranston (2005): The insects, An outline of Entomology by Blackwell publishing Ltd. PP. 61-65. 
Hegazi, E. M.Ramadan,M. M., Sabry, E,A. and Shbaan. M.A. (1978). Invertebrates; Epigeal Fauna. In: Systems Analysis of Mediterrean Desert University of Alexandria, Progress Report 4, Vol. 11 (3) pp. 88.

Jones, J. C. (1964): The Circulatory system of insects. In the Physiology of Insects. Vol. III, Ed. By M. Rockstein Academic Press Inc., N. Y. pp. 1-107.

Klowden, M. J. (2016): Physiological Systems in Insects. by Taylor \& Francis Group, LLC. pp. 365-382.

Lai - Fook, J. (1970): Haemocytes in Rhodnius sp. J. Morph., 130: 297-314

McCann, F.V. (1970): Physiology of Insect Hearts. Ann. Rev Entomol, 15: 173-200.

Osman, S.I, A. M. Shalaby and A.H.A. El- Zoheiry (1982): Anatomy and histology of the reproductive system of the adult black desert beetle Blaps sulcata Laporte. Bull. Fac. Sc. Alex. 22(4): 31-46.

Patton, R.L. (1963): Introductory Insect Physiology. W. B. Saunders Co, Philadelphia.

Romoser, W.S. (1973): The Science of Entomology. Macmillan Publishing C. Inc., N. Y. Collier Mac. Pub. London. pp. 449.

Roth, L.M. and Eisner, T. (1962): Chemical defenses of arthropods.Ann. Rev. Entomol., 7:107-136.

Shalaby, A. M.,Osman, S. I. and El- Zoheiry A. H. A. (1982): Anatomy and histology of the digestive system of the adult black desert Beetle Blaps sulcata Laporta. Bull. Fac. Sc. Alex. 22(4): 1-30.
Soliman, A. M \& Gad A.A. (2020): The impact of ascorbic acid, some nano materials and their mixtures on biological and physiological parameters of the mulberry silkworm Bombyx mori L. Alex. Sci. Exchange. J. 41 (3): 393398.

Sorour, J. (1993): Fine structure of pheromone glands in male Blaps polychresta (Coleoptera, Tenebrionidae). J. Insect Morphol. and Embryol. (In Press).

Tagi - Zade, F.A. and Gadzhizalov, D.M.(1989): Beetles as biological agents in fly control. Med. Parasitol. Mosk. 4: 91.

Tanagho, J.L.H.(1989): Biochemical studies on the fat body of Blaps sulcata Laporta and Blaps polychresta Forskal. M.Sc. Thesis. Faculty of Science. Alex. Univ., Egypt.

Wigglesworth,V. B.(1939): The principles of insect physiology. First Edition, Methuen Co., London. pp. 434.

Wigglesworth, V. B. (1972): The principles of insect physiology $7^{\text {th }}$ edition. pp.795.

Wigglesworth, V. B. (1979): Haemocytes and growth in insects. In insect haemocytes, edited by A.P. Gupta. Cambridge Univ., Press. pp. 303-318.

Zlotkin, S., M. Gurevitz and A. Shulov (1973): The toxic effects of phenoloxidase from the hemolymph of tenebrionid beetles. J. Insect physiol. 19(5): 1057-1065. 


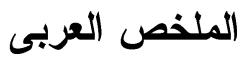

دراسات على الجهاز الدورى فى الخنفساء الصحراوية البالغة بلابس سولكاتا لابورتا

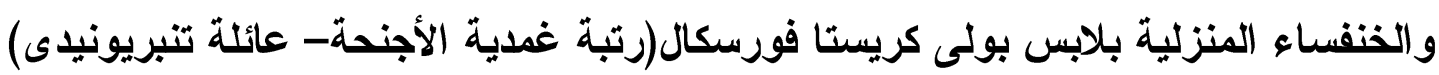

$$
\begin{aligned}
& \text { عبد المنعم حسن الزهيرى وصلاح الدين إبراهيم عثمان } \\
& \text { قسم علم الحيوان - كلية العلوم - جامعة الاسكندرية - مصر . }
\end{aligned}
$$

الغرض من هذه الدراسات هو وصف تثريحي وهسترلوجي للقلب و العضلات الجناحية و الخلايا الحول قلبية

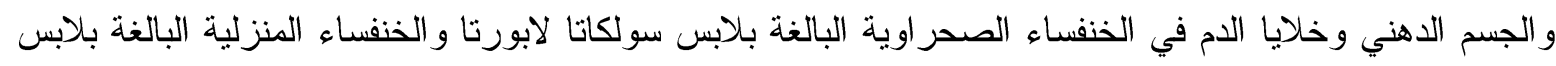
بولى كريستا فورسكال

يتكون الوعاء الظهرى فى كل من الخنفساء بلابس سولكاتا لابورتا وبلابس بولى كريستا فورسكال من أبهر

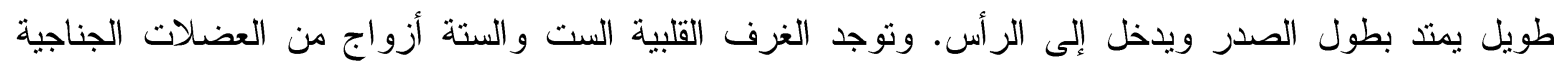

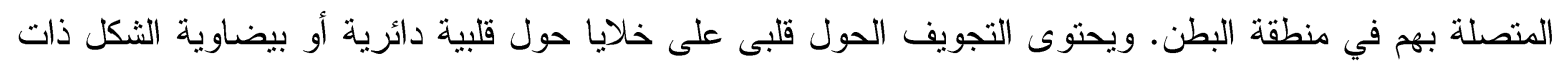

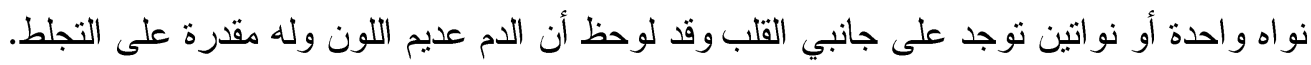

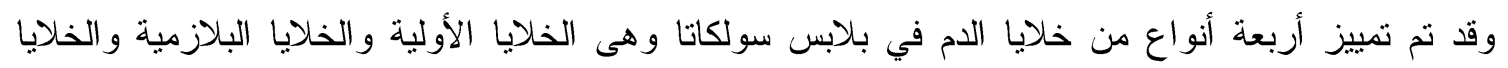

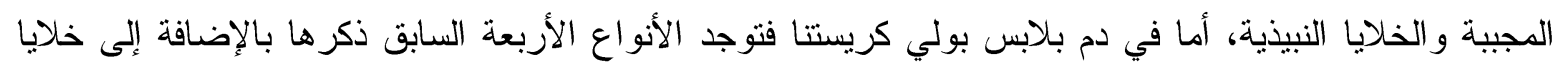
دموية دهنية غير حقيقية تظهر على سطح الجسم الدهني. 